\title{
Energética Molecular no CQE-IST: Fragmentos de uma Visão Pessoal
}

O meu envolvimento com a Energética Molecular - a visão moderna da Termoquímica - deu-se por volta de 1977, enquanto ainda estudante de Engenharia Química no Instituto Superior Técnico. No final do terceiro ano, muito por culpa do entusiasmo pela investigação que se vivia no Centro de Quimica Estrutural (CQE) [1], os meus interesses tinham-se deslocado da engenharia para a química e, em particular, para o estudo do modo como a energia das moléculas está relacionada com a sua estrutura e reactividade, isto é, a Energética Molecular.

O embrião do projecto de Energética Molecular surgira no CQE cerca de dois anos antes, quando os Professores Alberto Romão Dias (ARD) e Jorge Calado (JC) decidiram contratar um estudante de doutoramento para atacar um problema que cruzava simultâneamente a Química Organometálica (a especialidade de ARD) e a Termodinâmica (a especialidade de JC) [2-4]. A "vítima" foi o Professor José Artur Martinho Simões (JAMS) e o problema era o seguinte: no início da década de setenta conheciamse já bastantes compostos homolépticos $\left(M R_{n}\right)_{x}$ em que $M$ era um elemento representativo e $\mathrm{R}$ um ligando $\sigma$-hidrocarbilo (e.g. alquilo, arilo, etc.), estáveis à temperatura ambiente [5]. Porém, as tentativas para preparar compostos análogos com metais de transição regra geral falhavam e, as poucas sinteses bem sucedidas conduziam, normalmente, a substâncias com uma enorme instabilidade térmica. Por exemplo, o
$\mathrm{T}_{1}\left(\mathrm{CH}_{3}\right)_{4}$ decompõe-se pouco acima de $-78^{\circ} \mathrm{C}$ e o $\mathrm{W}\left(\mathrm{CH}_{3}\right)_{6}$ explode à temperatura ambiente [6]. Gerou-se assim a convicção de que a instabilidade observada poderia ter origem numa eventual debilidade das ligações metal de transiçãocarbono. Esta ideia foi, no entanto, posta em causa pelos grupos de Wilkinson e Lappert, os quais fizeram independentemente notar que os mecanismos de decomposição dos $\sigma$-hidrocarbilos de metais de transição não pareciam envolver directamente a cisão homolítica das ligações M-R e, como tal, a instabilidade térmica destes complexos não deveria reflectir necessariamente a maior ou menor "força" daquelas ligações [5,7]. A questão poderia ser esclarecida se se dispusesse de um conjunto de "energias de ligação" metal de transição-carbono suficientemente grande e variado, para permitir avaliar se, de um modo geral, eram fortes ou fracas. Ora, à época, os dados existentes eram muito poucos, e foi isto que motivou o nascimento do projecto de energética molecular no CQE, cujo objectivo inicial foi a determinação de entalpias de ligação metal de transição-alquilo em complexos do tipo diciclopentadienilo como, por exemplo, o $\mathrm{Mo}\left(\eta^{5}-\mathrm{C}_{5} \mathrm{H}_{5}\right)_{2}\left(\mathrm{CH}_{3}\right)_{2}$ (figura 1) [8]. Essa investigação rapidamente se alargou a outros tipos de ligação e o projecto acabou por centrar-se no estudo sistemático da energética de ligações entre metais de transição e uma grande variedade de ligandos (hidreto, halogeneto, alquilo, arilo, fosfina, tiolato, etc.) e da sua relação com a estrutura e a reac- tividade. 0 objectivo inicial foi, no entanto, alcançado: os resultados obtidos no $C Q E$, em conjunto com os de outros grupos (sobretudo europeus e americanos) que também se tinham interessado pela energética de compostos organometálicos, demonstraram, que, tal como Wilkinson e Lappert tinham suspeitado, as ligações metal-carbono não são necessariamente mais fracas para os metais de transição do que para os elementos representativos.

A estratégia delineada para determinar as entalpias de ligação metal-ligando nos complexos $M\left(\eta^{5}-C_{5} H_{5}\right)_{2} L_{2}(M=T$, $\mathrm{Zr}, \mathrm{Hf}, \mathrm{V}, \mathrm{Nb}, \mathrm{Ta}, \mathrm{Mo}, \mathrm{W} ; \mathrm{L}=\mathrm{H}$, halogénio, alquilo, arilo, fosfina, tiolato, etc.) baseava-se essencialmente no uso de duas técnicas: a calorimetria de solução-reacção e o método de efusão de Knudsen. A primeira permitia obter a entalpia de formação do complexo em estudo no estado cristalino $\Delta_{\mathrm{f}} H_{\mathrm{m}}^{0}$ (cr) e, a segunda, a sua entalpia de sublimação $\Delta_{\text {sub }} H_{\mathrm{m}}^{0}$. A partir destes dois dados determinava-se a correspondente entalpia de formação em fase gasosa $\Delta_{\mathrm{f}} H_{\mathrm{m}}^{0}$ (g) e, posteriormente, a variação média de entalpia associada à cisão homolítica de uma ligação $M-L,<D H>(M-L)$, ou seja a desejada "energia" da ligação $M$ L. O cálculo de $\langle D H>(M-L)$ baseava-se na reacção 1 e na equação 2 que dela decorre:

$\mathrm{M}\left(\eta^{5}-\mathrm{C}_{5} \mathrm{H}_{5}\right)_{2} \mathrm{~L}_{2}$ (g) $+2 \mathrm{Cl}(\mathrm{g}) \rightarrow$ $\mathrm{M}\left(\eta^{5}-\mathrm{C}_{5} \mathrm{H}_{5}\right)_{2} \mathrm{Cl}_{2}(\mathrm{~g})+2 \mathrm{~L}(\mathrm{~g})$

$<D H>(\mathrm{Mo}-\mathrm{L})=\frac{\Delta_{\mathrm{t}} H_{\mathrm{m}}^{\circ}}{2}+<D H^{\circ}>(\mathrm{Mo}-\mathrm{Cl})$ 


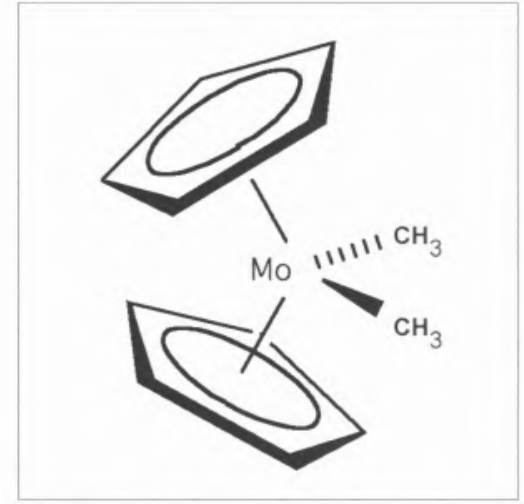

figura 1 Diciclopentadienilodimetilomolibdénio(IV), $\mathrm{Mo}\left(\eta^{5}-\mathrm{C}_{5} \mathrm{H}_{5}\right)_{2}\left(\mathrm{CH}_{3}\right)_{2}$

0 valor de $\Delta_{\mathrm{r}} H_{\mathrm{m}}^{0}$ (1), era obtido a partir de $\Delta_{1} H_{\mathrm{m}}^{0}\left[\mathrm{M}\left(\eta^{5}-\mathrm{C}_{5} \mathrm{H}_{5}\right)_{2} \mathrm{~L}_{2}, \mathrm{~g}\right]$ e dos valores de $\Delta_{1} H_{\mathrm{m}}^{0} \quad\left[\mathrm{M}\left(\eta^{5}-\mathrm{C}_{5} \mathrm{H}_{5}\right)_{2} \mathrm{Cl}_{2}, \mathrm{~g}\right]$, $\Delta_{\mathrm{t}} H_{\mathrm{m}}^{0}(\mathrm{Cl}, \mathrm{g})$ e $\Delta_{\mathrm{t}} H_{\mathrm{m}}^{0}(\mathrm{~L}, \mathrm{~g})$ disponíveis na

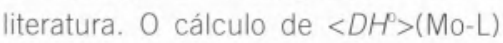
implicava ainda a estimativa de $<D H>(\mathrm{Mo}-\mathrm{Cl})$ usando um critério [4] cujos detalhes saem fora do âmbito deste artigo.

É claro que no início não existia no CQE qualquer tradição de trabalho em calorimetria de solução-reacção ou no método de Knudsen, nem tão pouco equipamento. A montagem e implementação destas técnicas foi uma aventura, e o espaço que abrigou as primeiras versões do calorímetro de solução-reacção e da célula de Knudsen foi baptizado de "Chez Arthur". Embora antigo, era (e é!) um laboratório óptimo para calorimetria, situado no rés-do-chão do Pavilhão de Química do IST. As paredes são grossíssimas e está semi-enterrado no chão, pelo que possui uma excelente estabilidade térmica. A placa que dizia "Chez Arthur" já não existe; mas, tanto quanto me lembro, o nome do laboratório foi inspirado no de um restaurante portuense (Chez Lapin) que o professor Martinho Simōes frequentava às vezes, quando aos fins-de-semana se deslocava ao grupo do Professor Manuel A. V. Ribeiro da Silva, na Faculdade de Ciências da Universidade do Porto, para realizar experiências de calorimetria de solução-reacção. Foi nessas deslocações, e noutras previamente realizadas ao grupo dos Professores Henry A. Skinner, Geoffrey Pilcher e Joseph A. Connor, em Manchester (Reino Unido), que inicialmente adquiriu a experiência em calori- metria de solução-reacção, que viria a utilizar na montagem do equipamento em Lisboa e a transmitir aos vários estudantes de doutoramento (entre os quais orientou com o Professor Romão Dias, no Instituto Superior Técnico.

Apanhei a montagem do laboratório mesmo no início. Pude assim seguir de perto a construção e teste da primeira versão do calorímetro de solução-reacção. A concepção básica deste apareIho, importada do grupo de Manchester, tem-se mantido ao longo dos anos e, como se verá adiante, o modelo actual (figura 2), presta ainda muito bom serviço. As experiências são em princípio muito simples. 0 vaso calorimétrico está mergulhado num banho de água cuja temperatura é controlada com grande precisão (tipicamente $\pm 0.001 \mathrm{~K}$ ). No ineu) que posteriormente orientou ou co-

terior do vaso calorimétrico está colocada uma ampola de vidro contendo a substância a estudar. Esta ampola é, a dada altura, quebrada no seio de uma solução onde existe um segundo reagente. A reacção que se segue provoca uma variação de temperatura (positiva se a reacção for exotérmica ou negativa se a reacção for endotérmica), que pode ser medida com um termómetro e corrigida utilizando um modelo matemático, de modo a obter a variação de temperatura, $\Delta T_{\text {ad }}$, que supostamente se mediria se o processo fosse adiabático. 0 valor de $\Delta T_{\text {ad }}$ permite, por sua vez, calcular a entalpia, $\Delta_{\mathrm{r}} \mathrm{H}$, associada à reacção em estudo em condições isotérmicas, através de:

$$
\Delta_{\mathrm{r}} H=\frac{\varepsilon \Delta T_{\mathrm{ad}}}{n}
$$

figura 2 Calorimetro de solução-reacçâo

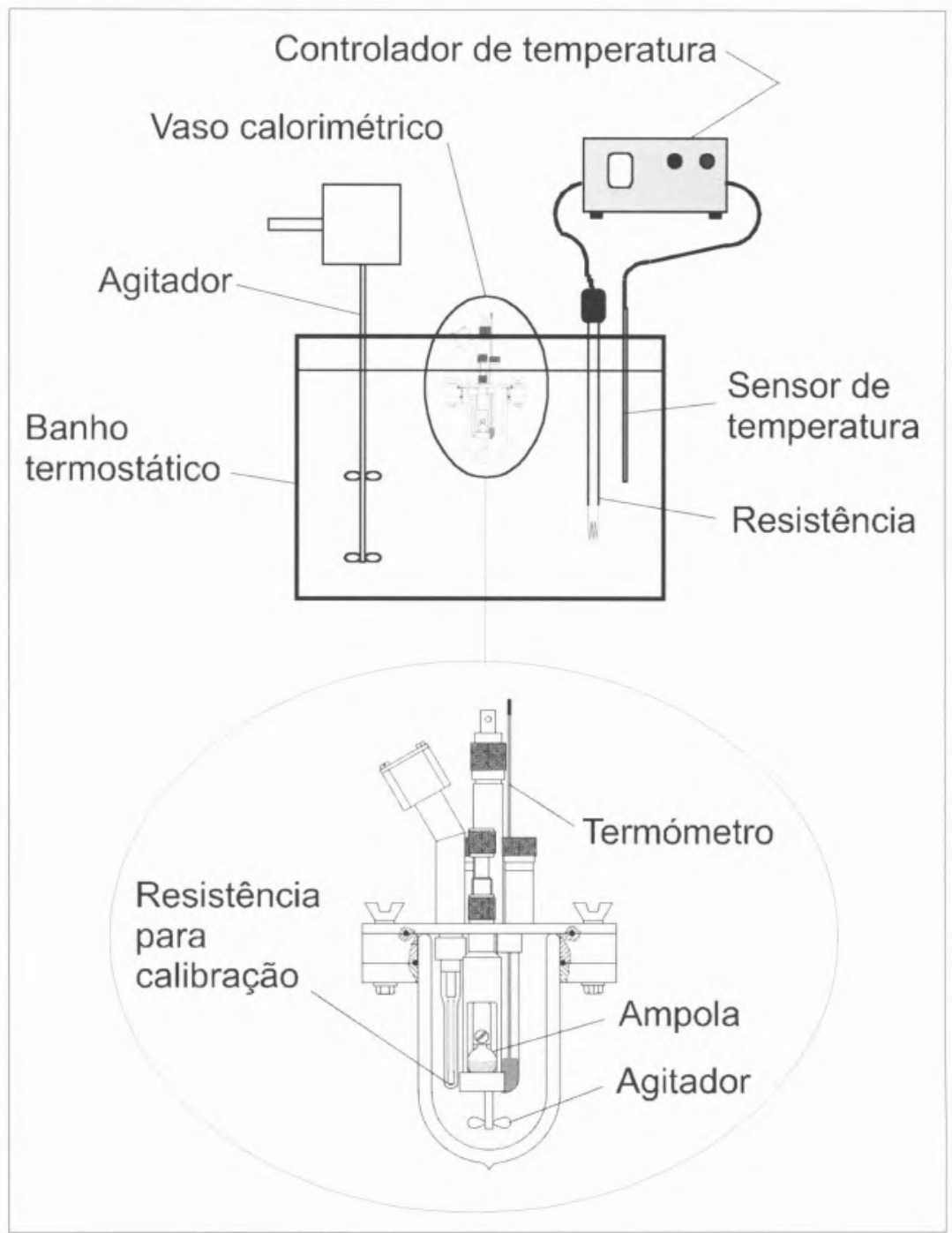


onde $n$ representa a quantidade de substância e $\varepsilon$ o equivalente energético do calorímetro. 0 uso da equação 3 implica a determinação prévia de $\varepsilon$ mediante uma calibração. No caso presente, trata-se de uma experiência análoga à experiência principal, em que se gera uma quantidade de calor conhecida, $Q$, no seio do vaso calorimétrico e se determina, simultaneamente, o valor de $\Delta T_{\text {ad }}$ que the corresponde. 0 calor é produzido fazendo passar uma corrente eléctrica de intensidade, I, através de uma resistência existente no interior do vaso calorimétrico (figura 2) durante um tempo $t$. Para o calcular determinam-se os valores de $t$, I e da queda de potencial, $V$, entre as extremidades da resistência $(Q=V / t)$, sendo $\varepsilon$ obtido a partir de:

$$
\varepsilon=\frac{V I t}{\Delta T_{\text {ad }}}
$$

Colaborei sobretudo no projecto e montagem do sistema de efusão de Knudsen, o que me valeu, aliás, o meu primeiro artigo [9]. Esta aparelhagem, cuja versão mais recente [10] está representada na figura 3 , permite, como atrás se referiu, determinar entalpias de sublimação de sólidos com base em medidas de pressão de vapor em função da temperatura. Numa experiência típica, a amostra é encerrada numa pequena caixa cilíndrica- a célula de Knudsen que possui no topo um pequeno orifício. A célula é inserida num bloco metálico que constitui a base de uma câmara de vácuo. A temperatura do bloco é mantida constante com o auxílio de um sistema de termostatização. No caso presente usam-se, consoante as necessidades, um forno (temperaturas altas) ou um banho de água (temperaturas próximas da ambiente), ligados a um controlador de temperatura. A experiência consiste em determinar a massa de sólido $m$ perdida pela célula, durante um intervalo de tempo $t$, à temperatura $T$. Essa perda de massa é originada pelo facto de, uma vez colocada a câmara em vazio, a pressão no exterior da célula ( $p_{e x}$ ser muito menor do que a pressão no seu interior (p). Se o sistema estiver bem projectado $p \gg p_{e x}$ e, portanto, $p_{e x} \approx 0$. Para além disso, o número de moléculas que atravessa o orifício por unidade de tempo deve ser suficientemente pequeno para que se possa admitir que a pressão no interior da célula ao longo da experiência é, de facto, a pressão de vapor da substância à temperatura de trabalho. Com base nesta informação obtém-se $p$ à temperatura $T$, através de:

$$
p=\frac{m}{A t}\left(\frac{2 \pi R T}{M}\right)^{1 / 2} \frac{1}{K_{\mathrm{c}} K_{\mathrm{hp}}}
$$

onde $A$ representa a área do furo (ca. $10^{-2}-10^{-3} \mathrm{~cm}^{2}$ ), $M$ a massa molar do composto em estudo, $R$ a constante dos gases perfeitos, e $K_{\mathrm{c}}$ e $K_{\mathrm{hpp}}$ dois parâmetros conhecidos, respectivamente, por factor de Clausing e factor de Hiby e Pahl. Estes factores destinam-se a corri- gir os desvios das condições experimentais a um modelo ideal que conduz à equação 5 desprovida de $K_{\mathrm{c}}$ e $K_{\text {hpp }}$. Segundo este modelo, a espessura do orifício é nula e o fluxo molecular através do furo é livre, ou seja, não depende da viscosidade do gás. $\mathrm{O}$ factor $K_{\mathrm{c}}$ permite ter em conta a espessura não nula do orifício $[11,12]$ e o factor $K_{\text {hp }}$ corrige pequenos desvios às condições de fluxo molecular livre [12,13]. O cálculo de ambos requer o conhecimento das dimensōes do orifício e, no caso de $K_{\text {hp }}$, é ainda exigido uma estimativa do diâmetro de colisão do composto em estudo.

Repetindo a experiência a diferentes temperaturas pode determinar-se a variação da pressão de vapor do sólido com a temperatura. Ajustando a equação de Clausius-Clapeyron (onde a é uma constante e $R$ a constante dos gases perfeitos) [14]

$$
\ln p=a-\frac{\Delta_{\mathrm{sub}} H_{\mathrm{m}}^{\mathrm{o}}}{R T}
$$

a estes dados, por regressão linear obtém-se uma recta cujo coeficiente angular $\left(-\Delta_{\text {sub }} H_{\mathrm{m}}^{\circ} / R\right)$ permite obter a entalpia de sublimação pretendida.

O estudo de compostos organometálicos foi durante muitos anos o fio condutor da investigação em energética molecular no CQE [2-4]. Porém, no início dos anos 90 ficou operacional no laboratório um microcalorimetro de combustão de bomba rotativa (figura 4), que só mais

figura 3 Sistema de efusão de Knudsen

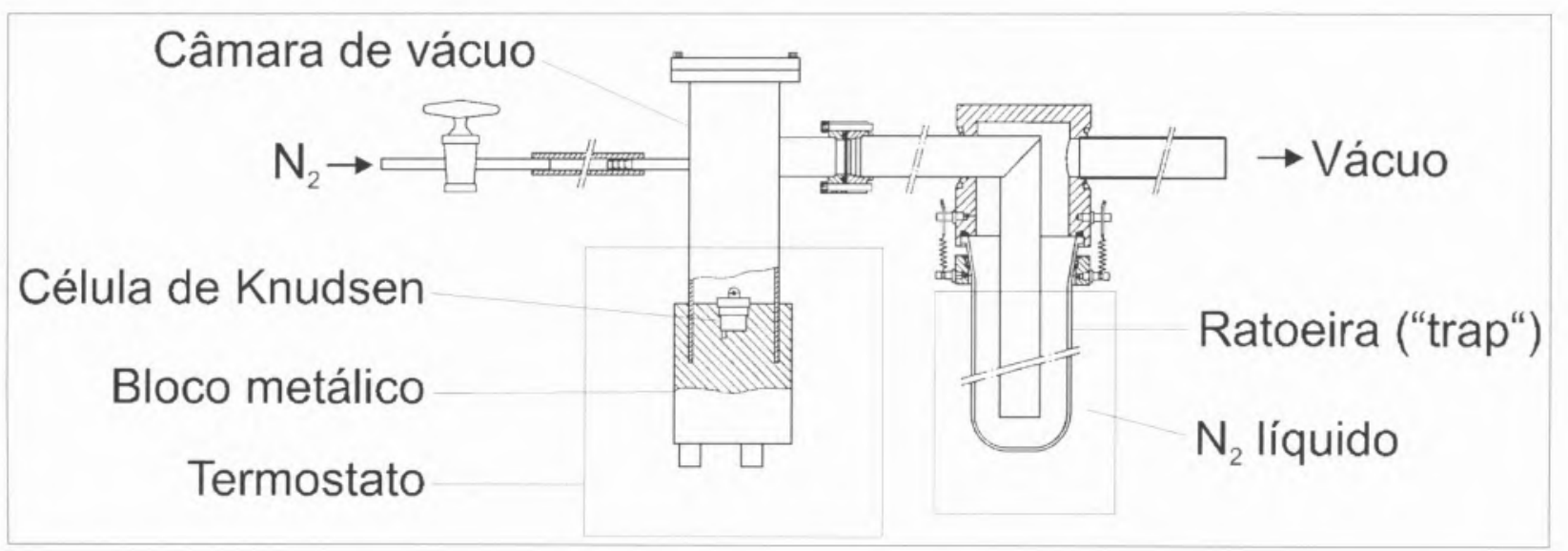


figura 4 Microcalorimetro de combustão

tarde descrevemos completamente na literatura $[15,16]$. Este instrumento permitiu pela primeira vez desviar o centro das atenções dos compostos organometálicos. As experiências são de algum modo parecidas com as efectuadas em calorimetria de solução-reacção. O composto a estudar, sob a forma de uma pastilha, é colocado num cadinho de platina dentro da bomba de combustão. Esta contém oxigénio a uma pressão de $3.04 \mathrm{MPa}$ (30 atm) e é introduzida no bloco calorimétrico onde está inserido um termómetro. 0 bloco encontra-se no interior de um sistema termostático. A reacção de combustão é iniciada levando ao rubro um fio de platina em contacto com a amostra, mediante a descarga de um condensador eléctrico. 0 processo é exotérmico e gera o aquecimento da bomba e do bloco calorimétrico. Tal como no caso da calorimetria de solução-reacção, a entalpia da reacção em estudo é obtida a partir da determinação de $\Delta T_{\text {ad }}$. Porém, no caso presente, a calibração não é eléctrica, baseando-se antes na reacção de combustão de uma amostra

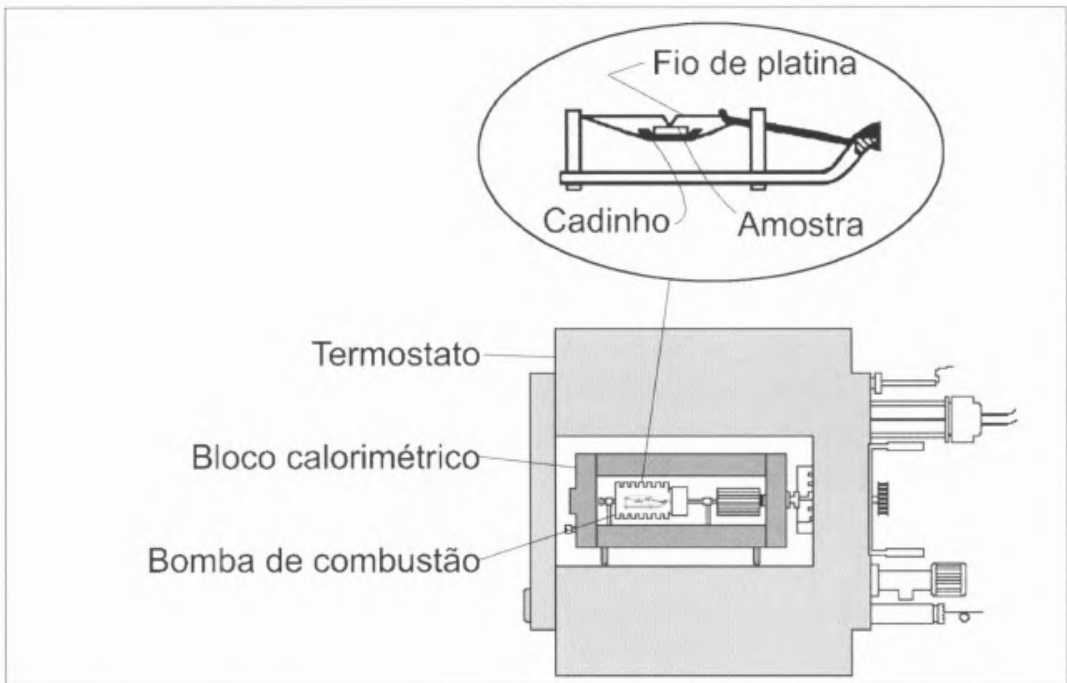

padrão de ácido benzóico cuja energia de combustão é conhecida.

O aparelho foi originalmente construído na Suécia, como resultado de um projecto de colaboração entre os Professores Stig Sunner e Margaret Månsson da Universidade de Lund (Suécia), e Henry A. Skinner e Geoffrey Pilcher da Universidade de Manchester (Reino Unido). Com o falecimento do Professor Sunner e a saída da Professora Månsson da Universidade de Lund o calorímetro nunca chegou a ultrapassar a fase de teste nas mãos dos seus construtores. Foi-me oferecido em 1986, quando ainda no decurso do meu projecto de doutoramento estava a trabalhar com o Professor Pilcher, em Manchester, na determinação da entalpia de formação do $W\left(\eta^{5}-\mathrm{C}_{5} \mathrm{H}_{5}\right)_{2} \mathrm{Cl}_{2}$. O Professor Ingemar Wadsö, que à data liderava o grupo de Lund, tinha decidido descontinuar o projecto de calorimetria de combustão no seu laboratório e contactou o Professor Pilcher à procura de alguém que estivesse disposto a dar utilização ao microcalorímetro de combustão. A calorimetria de combustão é geralmente a técnica mais adequada para estudar a termoquímica de compostos orgânicos e, há muito que a desejávamos implementar em Lisboa. A ideia inicial era utilizá-la para obter informação sobre moléculas orgânicas relevantes para o estudo dos sistemas organometálicos mas, como se verá a seguir, este objectivo foi rapidamente marginalizado. 0 facto de se tratar de um aparelho micro, utilizando tipicamente $10-20 \mathrm{mg}$ de amostra por ensaio, representava à partida uma grande vantagem sobre a técnica convencional (macro). Esta requer cerca de 0.5-1 g de amostra por ensaio, o que impede a sua aplicação a um grande número de compostos interessantes que apenas estão disponíveis em muito menores quantidades. 0 "coração" do aparelho chegou a Portugal ainda em 1986 e foram necessários cerca de cinco anos, para, em conjunto com o Dr. Hermínio Diogo, reunir o equipamento auxiliar necessário, tornar o calorímetro operacional e completar o nosso primeiro trabalho baseado nesta técnica. Tratou-se de um estudo sobre a energética da reparação de DNA pelas fotoliases do DNA [17].<smiles></smiles>

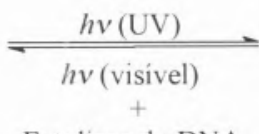

Fotoliase do DNA

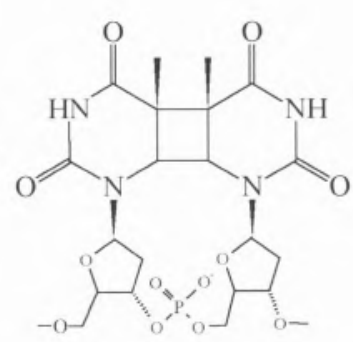


A exposição de DNA a radiação ultravioleta pode originar uma reacção de cicloadição entre duas pirimidinas vizinhas na dupla hélice conduzindo à formação de dímeros [18] (reacção 7)

Esta reacção constitui a lesão causada ao DNA por radiação ultra-violeta, com maior rendimento quântico. Numa grande variedade de organismos vivos o processo pode ser revertido, mediante uma reacção assistida pela luz, em que intervêm enzimas designados por fotoliases do DNA [19]. Conforme indicado na equação 7, a reparação da lesão envolve a cisão de um anel ciclobutano. Ora para a reacção 8:

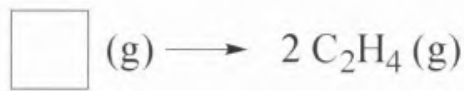

a $298.15 \mathrm{~K}$, verifica-se que $\Delta_{\mathrm{r}} H_{\mathrm{m}}^{\circ}=$ $76.5 \pm 0.8 \mathrm{~kJ} \cdot \mathrm{mol}^{-1}[20]$ e $T \Delta S_{\mathrm{m}}^{\circ}=51.4$ $\mathrm{kJ} \cdot \mathrm{mol}^{-1}$ [21] e, consequentemente, $\Delta, G_{\mathrm{m}}^{0}=25.1 \mathrm{~kJ} \cdot \mathrm{mol}^{-1}$. Este resultado poderia sugerir que o processo de reparação do DNA era endergónico $\left(\Delta_{\mathrm{r}} G_{\mathrm{m}}^{0}>\right.$ $0)$ e, por isso, termodinamicamente desfavorável. Para testar esta hipótese e investigar a "força motriz" da acção do enzima estudou-se a energética da reacção 9, que constitui um modelo da reacção 7. Determinaram-se as entalpias de formação dos compostos $\mathbf{1}$ e $\mathbf{2}$ (equação 10) por microcalorimetria de combustão e, com base nos valores obtidos, $\Delta_{r} H_{m}^{0}(1, c r)=-(1006.6 \pm 3.7)$ $\mathrm{kJ} \cdot \mathrm{mol}^{-1}$ e $\Delta_{4} H_{m}^{0}(\mathbf{2}, \mathrm{cr})=-(1116.6 \pm 3.7)$ $\mathrm{kJ} \cdot \mathrm{mol}^{-1}$, verificou-se que $\Delta_{\mathrm{r}} H_{\mathrm{m}}^{0}=$ $-(110.0 \pm 5.2) \mathrm{kJ} \cdot \mathrm{mol}^{-1}$. A reacção 9 é assim exotérmica e deve necessariamente ocorrer com aumento de entropia pelo que, contrariamente à reacção 8 , é exergónica. Os resultados deste estudo permitiram então concluir que, embora os fotoenzimas possam induzir reacções fortemente endergónicas mediante a formação de complexos enzima-substracto, neste caso, o papel das fotoliases deve ser apenas de natureza cinética.

Foi também o microcalorímetro de combustão que nos permitiu, dois anos depois (1993), abordar um problema muito "quente" na altura e, que, ao contrário do que pensávamos quando o trabalho terminou, ainda está por resolver: a determinação da entalpia de formação do $\mathrm{C}_{60}$ no estado cristalino [22]. $0 \mathrm{C}_{60}$ é o membro mais famoso de uma imensa família de formas alotrópicas de carbono designadas por fullerenos. A molécula, com a forma de uma bola de futebol (figura 5), tinha sido descoberta em 1985 [23] e isolada em 1990 [24]. Como é sabido, a descoberta valeu a Robert F. Curl e Richard E. Smalley da Universidade de Rice nos E.U.A., e a Harold W. Kroto, da Universidade de Sussex, no Reino Unido, o prémio Nobel da Química, em 1996. 0 valor de $\Delta_{t} H_{\mathrm{m}}^{0}$ $\left(\mathrm{C}_{60}, \mathrm{Cr}\right)$ era um dado chave para quantificar a estabilidade deste composto em relação às outras formas de carbono conhecidas e, também, para avaliar a fiabilidade das previsões de métodos computacionais usados para discutir, por exemplo, os mecanismos de formação dos fullerenos em fase gasosa. De facto, a gama de valores teoricamente previstos para a entalpia de formação do $C_{60}$ em fase gasosa que encontrámos na literatura entre 1987 e 1992 estendia-se de $1097 \mathrm{~kJ} \cdot \mathrm{mol}^{-1}$ a $4072 \mathrm{~kJ} \cdot \mathrm{mol}^{-1}$ [22]. Assim, sem a existência de um valor experimental de $\Delta_{\mathrm{f}} H_{\mathrm{m}}^{0}\left(\mathrm{C}_{60}, \mathrm{~g}\right)$ fiável, tornava-se impossivel validar os resultados dos diversos métodos teóricos. Como referimos anteriormente $\Delta_{1} H_{\mathrm{m}}^{0}(\mathrm{~g})=$ $\Delta_{\mathrm{t}} H_{\mathrm{m}}^{\circ}(\mathrm{cr})+\Delta_{\text {sub }} H_{\mathrm{m}}^{\circ}$ e, portanto, a obtenção de $\Delta_{4} H_{m}^{\circ}\left(\mathrm{C}_{60}, \mathrm{~g}\right)$ requeria o conhecimento de $\Delta_{\mathrm{f}} H_{\mathrm{m}}^{\circ}\left(\mathrm{C}_{60}, \mathrm{~cm}\right)$ e $\Delta_{\text {sub }}$ $H_{m}^{0}\left(C_{60}\right)$ Os valores de $\Delta_{\text {sub }} H_{m}^{\circ}\left(C_{60}\right)$ existentes na literatura antes de iniciarmos o trabalho, em 1992, encontravamse razoavelmente concordantes. Porém, no caso de $\Delta_{\mathrm{l}} H_{\mathrm{m}}^{\circ}\left(\mathrm{C}_{60}, \mathrm{cr}\right)$ encontrámos dois valores concordantes $(2282 \pm 14$ $\mathrm{kJ} \cdot \mathrm{mol}^{-1}$ [25], 2273 $\pm 15 \mathrm{~kJ} \cdot \mathrm{mol}^{-1}$ [26]) e um terceiro (2422 $\pm 14 \mathrm{~kJ} \cdot \mathrm{mol}^{-1}$ [27]) que deles se afastava cerca de $150 \mathrm{~kJ} \cdot \mathrm{mol}^{-1}$. As três determinações tinham sido efectuadas em laboratórios espalhados por várias partes do mundo (Alemanha, Japão e E.U.A.), usando diferentes amostras e diferentes calorímetros de combustão. Foi a existência desta grande discrepância que nos levou a tentar redeterminar a entalpia de formação do $\mathrm{C}_{60}$ no estado cristalino. Tivemos a sorte de conseguir convencer o grupo de $\mathrm{Ha}$ rold W. Kroto, Roger Taylor e David R. M. Walton, da Universidade de Sussex, no Reino Unido, a enviar-nos uns preciosos 50 mg de $\mathrm{C}_{60}$ ultrapuro para queimar (!):

$\mathrm{C}_{60}(\mathrm{cr})+60 \mathrm{O}_{2}(\mathrm{~g}) \rightarrow 60 \mathrm{CO}_{2}(\mathrm{~g})$

Convém realçar que, conforme mostra a equação 10 , a calorimetria de combus-<smiles>CC(=O)CN1C(=O)N2CC3CC(C2)C2C4C(=O)N(C)C(=O)N2CC3C41</smiles>

(cr)<smiles>CC(=O)Cn1ccc(=O)n(CC2CC3CN(C)C(=O)N2C3)c1=O</smiles>
2

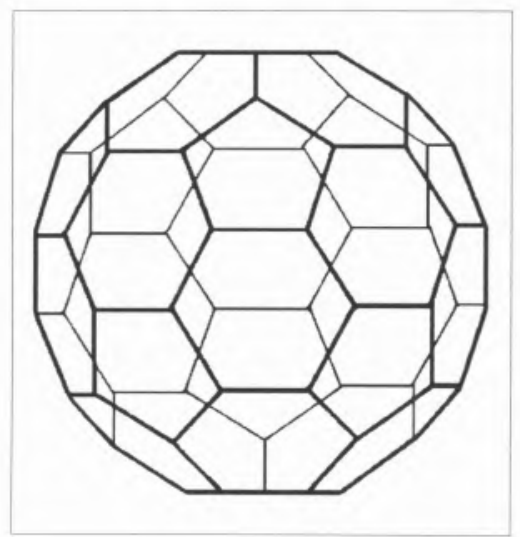


figura 6 Valores da entalpia de formação do $\mathrm{C}_{60}$ no estado cristalino publicados longo dos anos

tão é uma técnica destrutiva, isto é, não permite recuperar a amostra no final dos ensaios e que, em 1992, 50 mg era uma quantidade apreciável da reserva mundial de $\mathrm{C}_{60}$ ultrapuro. Nessa altura havia muito poucos grupos capazes de purificar e caracterizar convenientemente uma amostra de $\mathrm{C}_{60}$, e foi de facto uma sorte poder contar com a colaboração de um grupo que liderava a descoberta e caracterização de fullerenos. 0 contacto foi efectuado pelo Professor Martinho Simões, que à data ainda se encontrava no IST. As experiências foram realizadas pelo Dr. Hermínio Diogo (ainda estudante de doutoramento sob a supervisão dos Professores A. R. Dias e J. A. Martinho Simões) que conseguiu o milagre de realizar seis ensaios concordantes (sem falhar nenhum!) com massas de $\mathrm{C}_{60}$ a variar entre 3 e $16 \mathrm{mg}$. $\mathrm{O}$ valor médio obtido após os seis ensaios, $\Delta_{\mathrm{f}} H_{\mathrm{m}}^{\circ}\left(\mathrm{C}_{60}\right.$, $\mathrm{cr})=2278 \pm 14 \mathrm{~kJ} \cdot \mathrm{mol}^{-1}$ [22], estava em bom acordo com os dois primeiros resultados acima referidos e pensámos: -

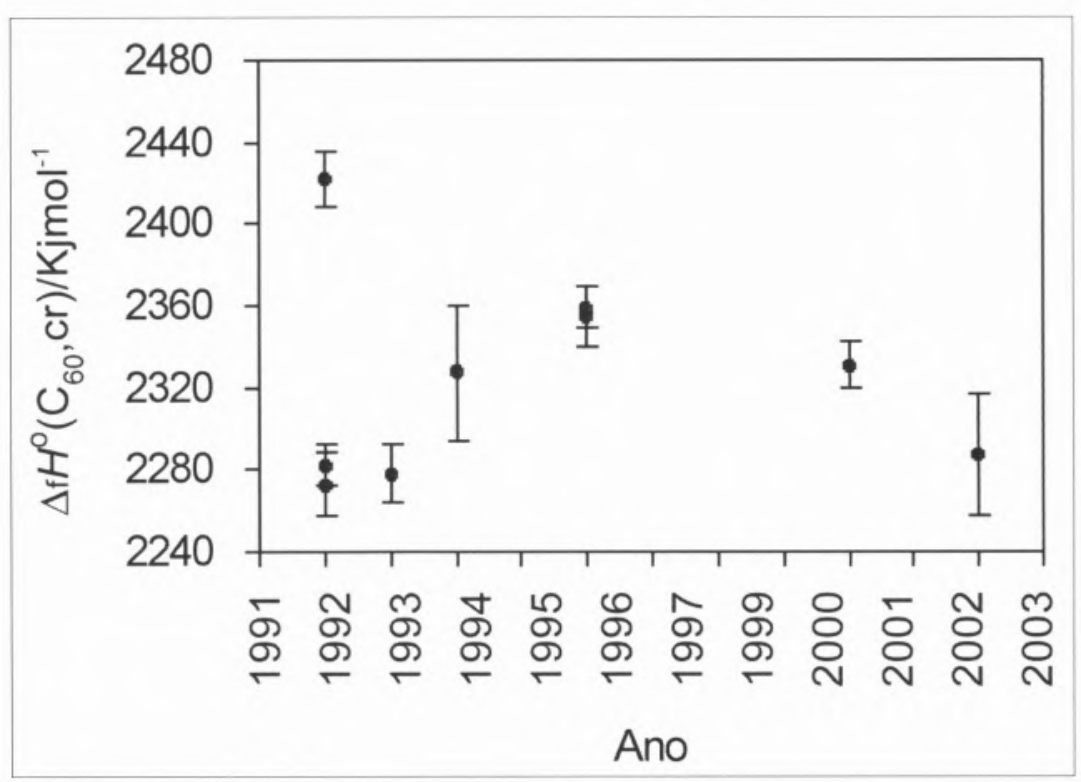

O assunto está arrumado! Surpreendentemente, um ano depois o valor da entalpia de formação do $\mathrm{C}_{60}$ cristalino começou a aumentar. Em 1994, utilizando uma nova amostra, o grupo alemão obteve $=2327 \pm 33 \mathrm{~kJ} \cdot \mathrm{mol}^{-1}$ [28] e, dois anos depois, um grupo russo e outro chinês chegaram respectivamente a $2355 \pm 15 \mathrm{~kJ} \cdot \mathrm{mol}^{-1}$ [29] e 2359 \pm 10 $\mathrm{kJ} \cdot \mathrm{mol}^{-1}$ [30]. Mais recentemente o valor de $\Delta_{\mathrm{l}} H_{\mathrm{m}}^{0}\left(\mathrm{C}_{60}, \mathrm{cr}\right)$ voltou a diminuir. No ano 2000 uma redeterminação pelo grupo chinês atrás referido conduziu a $\Delta_{\mathrm{f}} H_{\mathrm{m}}^{0}\left(\mathrm{C}_{60}, \mathrm{cr}\right)=2331 \pm 12 \mathrm{~kJ} \cdot \mathrm{mol}^{-1}[31]$ e já no corrente ano um grupo mexicano obteve $\Delta_{\mathrm{f}} H_{\mathrm{m}}^{0}\left(\mathrm{C}_{60}, \mathrm{cr}\right)=2287 \pm 30$ $\mathrm{kJ} \cdot \mathrm{mol}^{-1}$ [32]. A origem deste comportamento tipo "ioiô" observado para os resultados das determinações da entalpia de formação do $\mathrm{C}_{60}$ ao longo dos anos (figura 6), está ainda por descobrir e o seu esclarecimento vai certamente requerer o esforço concertado de vários laboratórios especializados em calorimetria de combustão e, sobretudo, na síntese e caracterização de fullerenos.
Embora a incerteza no valor experimental de $\Delta_{\mathrm{f}} H_{\mathrm{m}}^{0}\left(\mathrm{C}_{60}, \mathrm{cr}\right)$ seja ainda apreciável, os resultados existentes têm pelo menos o mérito de permitir reduzir extraordinariamente a gama de variação aceitável para as previsões dos métodos teóricos. Para além disso, de acordo com os oito resultados acima indicados, a entalpia de formação do $\mathrm{C}_{60}$ cristalino por átomo de carbono varia entre 37.9 $\mathrm{kJ} \cdot \mathrm{mol}^{-1}$ e $40.4 \mathrm{~kJ} \cdot \mathrm{mol}^{-1}$, mostrando, assim, que $0 \mathrm{C}_{60}$ é consideravelmente mais instável que a grafite e o diamante, cujas entalpias de formação são respectivamente $0 \mathrm{~kJ} \cdot \mathrm{mol}^{-1}$ e $1.895 \mathrm{~kJ} \cdot \mathrm{mol}^{-1}$ [33].

Posteriormente, também em colaboração com o grupo de Sussex, atacámos a determinação da entalpia de formação do $\mathrm{C}_{70}$, o segundo fullereno mais famoso [34]. A panorâmica actual, relativamente à incerteza no valor experimental de $\Delta_{\mathrm{f}} \mathrm{H}_{\mathrm{m}}^{\circ}\left(\mathrm{C}_{70}, \mathrm{cr}\right)$, não é muito diferente da descrita para o $\mathrm{C}_{60}$.

$$
\left.\mathrm{XCH}_{2} \mathrm{COOM}(\mathrm{cr}) \longrightarrow \frac{1}{n}+\mathrm{CH}_{2} \mathrm{COO}\right)_{\mathrm{n}}(\mathrm{pol})+\mathrm{MX}(\mathrm{cr}) \quad 11
$$
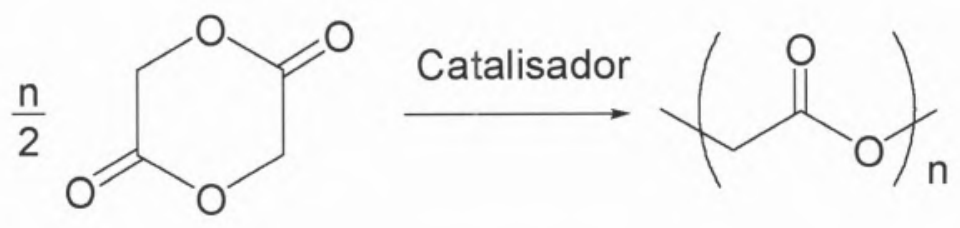
figura 7 Entalpias de polimerização dos haloacetatos de lítio e sódio (reacção 12) no estado padrão e a $298.15 \mathrm{~K}$ (dados em $\mathrm{kJ} \cdot \mathrm{mol}^{-1}$ )

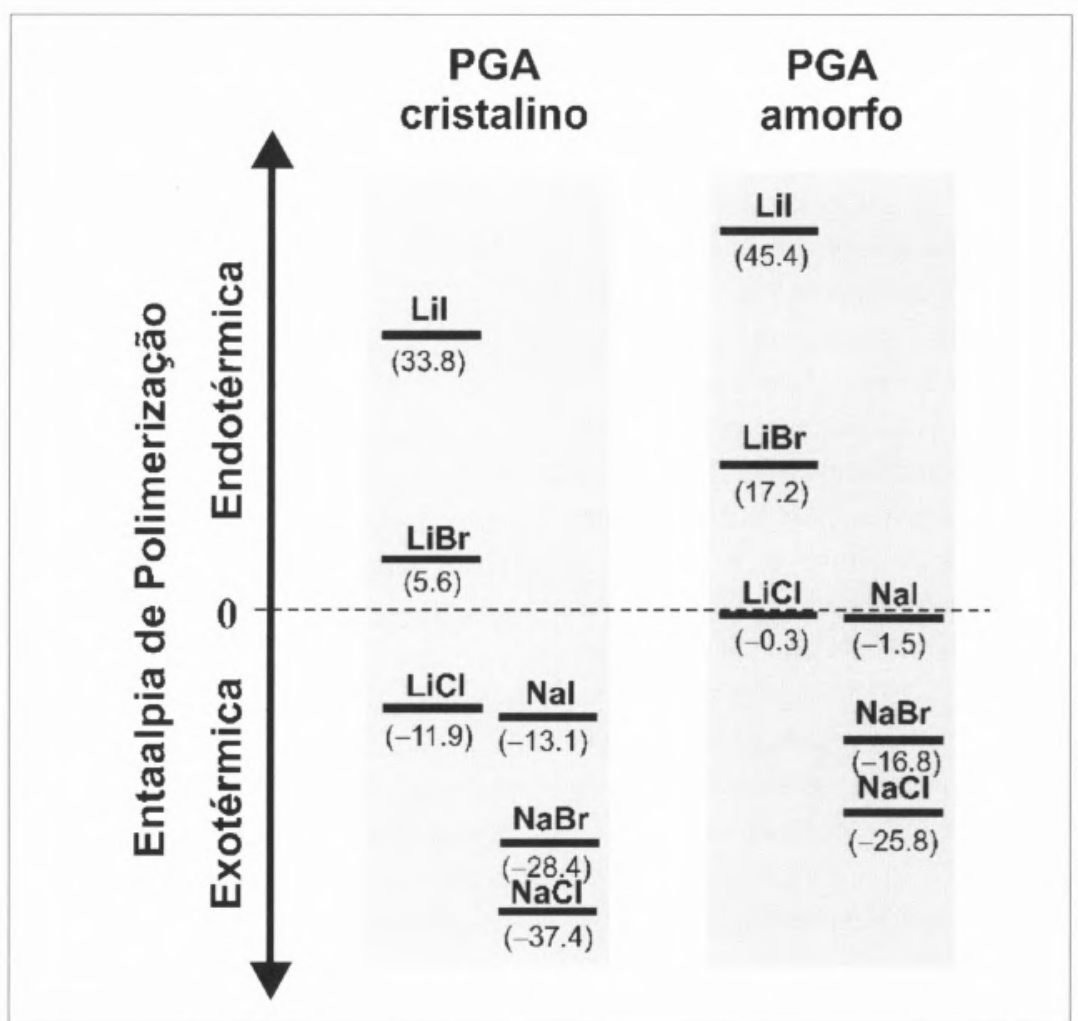

plo, usado em sistemas para administração controlada de medicamentos ("drug-delivery systems"), em matrizes para cultura de tecidos ("tissue engineering"), na fabricação de linhas de sutura cirúrgica autoabsorvíveis e em materiais para reparação de fracturas ósseas.

Convencionalmente, o PGA é sintetisado a partir da 1,4-dioxano-2,5-diona, usando um catalisador (e.g. $\mathrm{SbF}_{3}$ ), conforme indicado na reacção 12 .

Como alternativa, pode escolher-se a reacção 11, que foi descoberta por Hoffman em 1857, quando, trabalhando sob a orientação de Kekulé, decidiu estudar a policondensação do cloroacetato de potássio [36]. Esta reacção tinha passado praticamente despercebida até cerca de 1996, altura em que se tomou consciência que podia ser um método eficiente para preparar poliglicolatos com micromorfologia e porosidade controladas [37]. De facto, a reacção conduz a uma mistura íntima de poliglicolato e de sal MX. Removendo este último por lavagem com água obtém-se um poliglicolato altamente poroso, cuja porosidade depende da natureza do material de partida [37]. Esta possibilidade de controlo da porosidade e da micromorfologia é, obviamente, muito interessante tendo em conta as aplicações médicas. A reacção apresenta também vantagens evidentes do ponto de vista ambiental, uma vez que não implica a

\section{Tabela 1}

Decomposição da entalpia de reacção 11 em termos das entalpias de rede das espécies $\mathrm{XCH}_{2} \mathrm{COOM}_{\text {e }} \mathrm{MX}$ e da entalpia da reacção 15 (dados em $\mathrm{kJ} \cdot \mathrm{mol}^{-1}$ )

\begin{tabular}{cccccc}
\hline $\mathbf{M}$ & $\mathbf{X}$ & $\Delta_{\text {lat }} \boldsymbol{H}_{\mathrm{m}}\left(\mathbf{X C H}_{\mathbf{2}}\right.$ COOM) & $\Delta_{\mathrm{r}} \boldsymbol{H}_{\mathrm{m}}(\mathbf{1 5})$ & $-\Delta_{\text {lat }} \boldsymbol{H}_{\mathrm{m}}(\mathrm{MX})$ & $\Delta_{\mathrm{r}} \boldsymbol{H}_{\mathrm{m}}(\mathbf{1 1})$ \\
\hline $\mathrm{Li}$ & $\mathrm{Cl}$ & 888.8 & -40.7 & -860.0 & -11.9 \\
& $\mathrm{Br}$ & 887.2 & -64.0 & -817.6 & 5.6 \\
$\mathrm{Na}$ & $\mathrm{Cl}$ & 789.7 & -40.7 & -786.5 & -37.4 \\
& $\mathrm{Br}$ & 787.3 & -64.0 & -751.7 & -28.4
\end{tabular}


eliminação de solventes ou de catalisadores metálicos.

Antes de principiarmos o estudo destes sistemas no início do corrente ano, havia já um consideravel número de aspectos estruturais e de reactividade que tinham sido investigados sistematicamente, recorrendo a um largo espectro de técnicas experimentais [37]. Mas não se compreendia, por exemplo, a razão pela qual o $\mathrm{ClCH}_{2} \mathrm{COONa}$ polimerizava rapidamente a $471 \mathrm{~K}$ e o $1 \mathrm{CH}_{2} \mathrm{COONa}$ se decompunha a $493 \mathrm{~K}$ sem a ocorrência de polimerização. Para tentar discutir a origem destas observações de uma perspectiva termodinâmica, procedeu-se a uma análise da energética da reacção 11 para $\mathrm{M}=\mathrm{Li}$, $\mathrm{Na}$ e $\mathrm{X}=\mathrm{Cl}, \mathrm{Br}, \mathrm{I}$, com base em resultados de calorimetria de combustão e calorimetria de solução-reacção. A calorimetria de solução-reacção permitiu obter as entalpias de formação dos vários haloacetatos de sódio e lítio, a partir da determinação experimental da entalpia da seguinte reacção, $\Delta_{\mathrm{r}} H_{\mathrm{m}}^{0}$ (13):

$\mathrm{XCH}_{2} \mathrm{COOM}(\mathrm{cr})+\mathrm{HCl}(\mathrm{aq}) \rightarrow \mathrm{MCl}(\mathrm{cr})$ $+\mathrm{XCH}_{2} \mathrm{COOH}$ (cr)

A calorimetria de combustão conduziu aos valores de $\Delta_{4} H_{m}^{\circ}\left(X_{2} \mathrm{CH}_{2} \mathrm{COOH}, \mathrm{cr}\right)$ [37], que são necessários para calcular $\Delta_{1} H_{\mathrm{m}}^{\circ}\left(\mathrm{XCH}_{2} \mathrm{COOM}, \mathrm{cr}\right)$ a partir de $\Delta_{t} H_{m}^{\circ}$.(13) Neste âmbito contámos, mais uma vez, com a colaboraçāo do grupo do Professor Ribeiro da Silva, no Porto, que nos disponibilizou o calorímetro de combustão de bomba macro necessário às determinações. A primeira conclusão deste estudo está resumida na figura 7, que mostra a variação da entalpia da reacção 11 em função da natureza do metal $\mathrm{M}$ e do halogeneto $\mathrm{X}$, e da cristalinidade do polimero (as entalpias de formação do poliglicolato amorfo e cristalino estavam disponiveis na literatura). Nota-se, claramente que, tal como observado, a reacção é mais favorável (mais exotérmica) para os sais de sódio do que para os de lítio.

Uma análise mais profunda da origem desta tendência pôde ser efectuada decompondo a reacção 11 nos seguintes processos hipotéticos:

$$
\begin{aligned}
& \left.\mathrm{XCH}_{2} \mathrm{COOM}(\mathrm{cr}) \rightarrow \mathrm{M}^{+}(\mathrm{g})+\mathrm{XCH}_{2} \mathrm{COO}^{-} \mathrm{g}\right) \quad \Delta_{\text {at }} H_{\mathrm{m}}^{\circ}\left(\mathrm{XCH}_{2} \mathrm{COOM}\right) \\
& \left.\mathrm{XCH}_{2} \mathrm{COO}^{-} \mathrm{g}\right)-\frac{1}{n}+\mathrm{CH}_{2} \mathrm{COO} t_{n}(\mathrm{pol})+\mathrm{X}^{-}(\mathrm{g}) \Delta_{\mathrm{r}} H_{\mathrm{m}}^{\circ}(16) \\
& \mathrm{M}^{+}(\mathrm{g})+\mathrm{X}(\mathrm{g}) \rightarrow \mathrm{MX}(\mathrm{cr})-\Delta_{\text {lat }} H_{\mathrm{m}}^{\circ}(\mathrm{MX})
\end{aligned}
$$

A entalpia da reacção 14 corresponde à entalpia de rede do $\mathrm{XCH}_{2} \mathrm{COOM}, \Delta_{\mathrm{lat}} H_{\mathrm{m}}^{\circ}$ $\left(\mathrm{XCH}_{2} \mathrm{COOM}\right)$, e a entalpia da reacção 16 representa o simétrico da entalpia de rede do sal MX, $\Delta_{\text {lat }} H_{\mathrm{m}}^{\circ}(\mathrm{MX})$. Na reacção 15 uma ligação carbono-halogénio é cindida para originar poliglicolato e $\mathrm{X}$. Admitindo arbitrariamente que o PGA formado na reacção 11 possui uma cristalinidade de $100 \%$, e calculando as entalpias das reacçōes 14 a 16 com base em valores por nós obtidos ou retirados da literatura, foi possivel chegar aos resultados indicados na Tabela 1. Estes mostraram que a entalpia de rede dos sais acetato é independente da natureza do halogeneto X. Para além disso, embora na reacção 15 a quebra da ligação C-Br com formação de $\mathrm{Br}$ seja 23.3 $\mathrm{kJ} \cdot \mathrm{mol}^{-1}$ mais favorável do que a cisão da ligação $\mathrm{C}-\mathrm{Cl}$ com a formação de $\mathrm{Cl}$, esta diferença não é suficientemente elevada para ultrapassar a diferença entre as entalpias de rede dos sais MX que é favorável ao $\mathrm{MCl}$. Assim, a diminuiçăo da tendência dos haloacetatos $\mathrm{XCH}_{2} \mathrm{COOM}(\mathrm{M}=\mathrm{Li}, \mathrm{Na} ; \mathrm{X}=\mathrm{Cl}, \mathrm{Br}, \mathrm{I})$ para polimerizar quando $\mathrm{X}$ varia ao longo da série $\mathrm{Cl} \rightarrow \mathrm{Br} \rightarrow$ I, parece ser essencialmente determinada pelo valor da entalpia de rede dos sais MX.

Os exemplos acima apresentados ilustram alguns dos meus interesses cientificos da última década. Mas, a história não estaria completa sem referir que todo este trabalho se tem integrado num projecto mais alargado, que envolve, para além do grupo do Centro de Química Estrutural, dois outros grupos totalmente independentes: um na Faculdade de Ciências da Universidade de Lisboa, liderado pelo Professor J. A. Martinho Simões e outro no Instituto Tecnológico e Nuclear, liderado pelo Dr. João Paulo Leal. Na Faculdade de Ciências da Universidade de Lisboa usa-se calorimetria fotoacústica para estudar a energética de radicais em soluçāo [3]. Existe ainda uma vertente de Química Computacional centrada numa partilha de estudantes de doutoramento com o professor Benedito Cabral do Grupo de Física Matemática do Complexo II. No ITN está disponivel um calorímetro de solução-reacção, especialmente projectado para estudar compostos altamente sensiveis ao oxigénio e à humidade, e um espectrómetro de ressonância ciclotrónica de iões com transformada de Fourier, utilizado para estudar reacções iāo-molécula em fase gasosa [39]. O núcleo deste "supergrupo", a que normalmente chamamos "Grupo de Termoquimica de Lisboa", nasceu de facto no Centro de Química Estrutural do Instituto Superior Técnico em torno do Professor Martinho Simões, antes da sua transferência para a FCUL, e tem-se mantido unido apesar de os seus membros transitarem, por vezes, de instituição. Embora o trabalho em curso envolva muitas vezes apenas um dos grupos, é discutido por todos em reuniões, que normalmente decorrem rotativamente com uma periodicidade mensal, numa das instituições. A utilização do equipamento disponivel e das verbas obtidas em projectos conjuntamente submetidos é totalmente flexível. Esta fortíssima interacção que é, também, obviamente, baseada numa grande amizade, temnos beneficiado a todos, uma vez que a maioria dos problemas interessantes em energética molecular necessitam ser abordados usando diversas metodologias experimentais e teóricas.

Resta, por último, acrescentar que, para além da importante interacção com os vários membros do Grupo de Termoquímica de Lisboa exteriores ao IST, grande parte do trabalho realizado no CQE tem sido levado a bom porto graças à colaboração do Dr. Hermínio Diogo, que comigo tem partilhado a responsabilidade 
da manutenção do laboratório de termoquímica em velocidade de cruzeiro, e ao entusiasmo de alguns ex e actuais estudantes de doutoramento (Paulo Nunes, Rui Centeno Santos, Ana Lúcia Lagoa). Crucial tem também sido o fianciamento concedido ao longo dos anos pela Fundação para a Ciência e a Tecnologia presentemente através do projecto POCTI/199/QUI/35406.

\section{Referências}

[1] Ver a entrevista ao Prof A. Romão Dias em: M. J. Melo, F. Pina Bol. Soc. Port. Quim. 2001, N. ${ }^{\circ} 83,17$.

[2] M. E. Minas da Piedade, J. A. Martinho Simões Rev. Port. Quím. 1997, 4, 45.

[3] J. A. Martinho Simōes Bol. Soc. Port. Quim. 2001, N. ${ }^{\circ} 83,30$.

[4] H. P. Diogo, M. E. Minas da Piedade, J. A. Martinho Simões, C. Teixeira J. Organometal. Chem. 2001, 632, 188

[5] P. J. Davidson, M. F. Lappert, R. Pearce Chem. Rev. 1976, 76, 219.

[6] Comprehensive Organometallic Chemistry; G. Wilkinson, F. G. A. Stone, E. W. Abel, Eds.; Vol. 3; Pergamon Press: Oxford, 1982; pag. 459 e 1308.

[7] G. Wilkinson in: Proceedings of the 5th International Conference on Organometallic Chemistry; Moscow 1971; Butterworths: London, 1972.

[8] J. C. G. Calado, A. R. Dias, J. A. Martinho Simões J. Chem. Soc., Chem. Com.

$1978,17,737$

[9] A. R. Dias, J. C. G. Calado, A. R. Dias, M. E. Minas da Piedade, J. A. Martinho Simões Rev. Port. Quím. 1980, 22, 57.

[10] H. P. Diogo, M. E. Minas da Piedade, A.

C. Fernandes, J. A. Martinho Simões, M. A.

V. Ribeiro da Silva, M. J. S. Monte Thermochimica Acta 1993, 228, 15.
[11] The Characterization of High Temperature Vapors; J. L. Margrave Ed.; John Wiley: New York, 1967

[12] J. W. Edwards, G. L. Kington Trans. Faraday Soc. 1962, 58, 1323.

[13] P. C. Carman Flow of Gases Through Porous Media; Butterworths: London, 1956. p 64

[14] P. W. Atkins, J. de Paula Physical Chemistry; 7th Ed; Oxford University Press: Oxford, 2001

[15] H. P. Diogo, M. E. Minas da Piedade Chem. Thermodynamics 1995, 27, 197.

[16] R. C. Santos, H. P. Diogo, M. E. Minas da Piedade J. Chem. Thermodynamics 1999, 31, 1417.

[17] H. P. Diogo, A. R. Dias, A. Dhalla, M. E. Minas da Piedade, T. P. Begley J. Org. Chem. 1991, 56, 7340.

[18] Ver, por exemplo, J. Cadet, P. Vigny Bioorganic Photochemistry; $\mathrm{H}$. Morrison Ed. Wiley: New York, 1990; Vol 1, p 1.

[19] Ver, por exemplo, G. M. Myles, A. Sancar Chem. Res. Toxicol. 1989, 2, 197.

[20] J. B. Pedley Thermochemical Data and Structures of Organic Coumpounds; TRC Data Series, Vol. I; Thermodynamics Research Center: College Station, 1994

[21] D. R. Stull, E. F. Westrum, Jr., G. C. Sinke The Chemical Thermodynamics of Organic Compounds; Wiley: New York, 1969.

[22] H. P. Diogo, M. E. Minas da Piedade, T. J. S. Dennis, J. P. Hare, H. W. Kroto, R. TayIor, D. R. M. Walton J. Chem. Soc., Faraday Trans. 1993, 89, 3541

[23] H. W. Kroto, J. R. Heath, J. R. O'Brien, S. C. Curl, R. Smalley Nature 1985, 318 162

[24] W. Krätschmer, L. D. Lamb, K. Fostiropoulos, D. R. Huffman Nature 1990, 347 354.

[25] H.-D. Beckhaus, C. Rüchardt, M. Kao, F. Diederich, C. S. Foote Angew. Chem. Int Ed. Engl. 1992, 31, 63

[26] (a) T. Kiyobayashi, M. Sakiyama Annual Report of Microcalorimetry Research Center, Faculty of Science, Osaka University, 1992
13, 58. (b) T. Kiyobayashi, M. Sakiyama Fullerene Sci. Technol. 1993, 1, 269

[27] W. V. Steele, R. D. Chirico, N. K. Smith, W. E. Billups, P. R. Elmore, A. E. Wheeler J. Phys. Chem. 1992, 96, 4731

[28] H.-D. Beckhaus, S. Verevkin, C. Rüchardt, F. Diederich, C. Thilgen, U.-H. ter Meer, H. Mohn, W. Müller, C. S. Foote Angew. Chem. Int. Ed. Engl. 1994, 33, 996.

[29] V. P. Kolesov, S. M. Pimenova, V. K. Pavlovich, N. B. Tamm, A. A. Kurskaya J. Chem. Thermodynamics 1996, 28, 1121.

[30] A. Xu-wu, H. Jun, B. Zheng J. Chem. Thermodynamics 1996, 28, 1115 .

[31] A. Xu-wu, H. Jun Thermochimica Acta 2000, 352/353, 273.

[32] A. Rojas, L. A. Torres in: Abstracts of the 17th IUPAC Conference on Chemical Thermodynamics, Rostock, Germany, 2002.

[33] D. D. Wagman, W. H. Evans, V. B. Parker, R. H. Schumm, I. Halow, S. M. Bailey, K. L. Churney, R. L. Nuttall The NBS Tables of Chemical Thermodynamics Properties, J. Phys Chem. Ref. Data 1982, 11, Supplement no. 2.

[34] H. P. Diogo, M. E. Minas da Piedade, A. D. Darwish, T. J. S. Dennis J. Phys. Chem. Solids 1997, 58, 1965.

[35] A. L. C. Lagoa, H. P. Diogo, M. E. Minas da Piedade, K. Schwarz, M. Epple J. Phys. Chem. B, 2002, 106, 10764.

[36] R. Hoffmann Justus Liebigs Ann. Chem. 1857, 102, 1 .

[37] A. L. C. Lagoa, H. P. Diogo, M. P. Dias, M. E. Minas da Piedade, L. M. P. F. Amaral, M. A. V. Ribeiro da Silva, J. A. Martinho Simões, R. C. Guedes, B. J. Costa Cabral, K. Schwarz, M. Epple Chem. Eur. J. 2001, 7. 483.

[38] O. Herzberg, M. Epple Eur. J. Inorg. Chem. 2001, 1395

[39] Sobre esta técnica ver J. Marçalo Bol. Soc. Port. Quim. 1997, N.66, 32.

Só em Ciência se pode amar o que se destrói, se pode continuar o passado negando-o, se pode venerar o mestre contradizendo-o. (...) Só há por isso Ciência com uma aprendizagem contínua. É esta a Escola que a Ciência deve instaurar. Quando isso acontecer, as forças sociais inverter-se-ão, e será a Sociedade a organizar-se para a Escola, e não a Escola a organizar-se para a Sociedade. 


\section{Agora em Portuguêst Unlivrodereferênciaparatodosos Oúmincost}

Porque é necessário saber identificar uma espécie química por meio de uma palavra escrita ou pronunciada;

Para que o leitor, ou simplesmente o ouvinte, possa deduzir a estrutura a partir do nome, os nomes dos compostos devem ter tanta relação quanto possivel com as suas estruturas;

$$
\text { C C }
$$

E como tudo isto requer um sistema de princípios e de regras, cuja aplicação dá origem a uma nomenclatura sistemática,

Aparece, agora em PORTUGUÊS, o Guia IUPAC para a Nomenclatura de Compostos Orgânicos que actualiza o conjunto de regras contidas na última edição de Nomenclature of Organic Chemistry e permite ao utilizador criar nomes correctos, na nossa língua, adaptados a cada caso particular.

\section{RESULTADO DE UM EXAUSTIVO}

$$
\text { TRABALHO DE CONSULTA }
$$

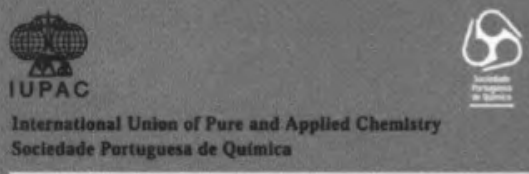

Guia IUPAC para a

Nomenclatura de Compostos Orgânicos

Tradução Portuguesa

nas Variantes Europeia e Brasileira

\section{Tradutores}

- Ana Cristina Fernandes - Universidade Lusófona de Humanidades e Tecnologias de Lisboa

- Bernardo Herold - Instituto Superior Técnico da Universidade Técnica de Lisboa

- Hernâni Maia - Universidade do Minho

- Amélia Pilar Rauter - Faculdade de Ciências da Universidade de Lisboa

- José Augusto Rosário Rodrigues - Universidade Estadual de Campinas do Estado de São Paulo

C N

N C ADAPTADO À LÍNGUA PORTUGUESA

Inclui referência à variante brasileira sempre que esta seja diferente da europeia 